\title{
SEMINAL VESICLE CYST: A RARECASE REPORT
}

\author{
Md Abdur Rakib', Md Shahidul Islam², S M Shameem Waheed ${ }^{3}$, Md Ashif Chwdhury ${ }^{4}$
}

\begin{abstract}
Seminal vesicle cysts are unusual but treatable causes of lower urinary tract symptoms. Transrectal ultrasonography is a good method for initial evaluation of seminal vesicle cysts. Endorectal magnetic resonance imaging should be reserved for the cases whose ultrasonographic results are not conclusive. Treatment should be restricted to symptomatic patients. Transvesical approach and laparoscopy in the hands of an experienced urologist are the best methods for resection of seminal vesicle cysts. In this article, a case of congenital seminal vesicle cysts is presented and the clinical symptoms, diagnosis, and management are discussed.
\end{abstract}

Keywords: acquired, congenital, seminal vesicle cyst.

Bangladesh J. Urol. 2019; 22(2): 106-109

\section{Introduction}

Cysts of seminal vesicle are rare. Acquired cysts, due to obstruction of ejaculatory duct, are the sequelae of an inflammatory process such as prostatitis, seminal vesiculitis, and prostate surgery[1]. Congenital cysts are associated with ipsilateral renal agenesis or dysplasia in two-thirds of patients. The majority of patients are asymptomatic. Seminal vesicle cysts usually present in the second and third decades of life and are predominantly seen in white patients[2]. We present here, a case of this unusual condition, and the management.

\section{Case Report}

A 21-year aged young boy, a student of Engineering Institute was referred to the Urologydepartment $\mathrm{CMH}$ Dhaka with the complains of pelvic discomfort and scrotal swelling for thepast few months with no history of dysuria,hematuria, painful ejaculation or hematospermia. Physical examination was unremarkable except for a right sided spermatocele and a soft cystic mass on the superior aspect of the prostate, on digital rectal examination. Laboratory data including urine analysis

1. Col (Professor) Md Abdur Rakib, Urology Centre, Combined Military Hospital Dhaka, Dhaka Cantonment

2. Brig Gen (Professor) Md Shahidul Islam, Head of the department of Urology Centre, Combined Military Hospital Dhaka, Dhaka Cantonment

3. Combined Military Hospital Dhaka, Dhaka Cantonment Mob-01769014704

3. Lt Col (Associate Professor), Urology Centre, Combined Military Hospital Dhaka, Dhaka Cantonment, Mob01715001615

Correspondence: Col (Professor) Md Abdur Rakib, Urology Centre, Combined Military Hospital Dhaka, Dhaka Cantonment

Received: 05 February 2019

Accepted: 10 May 2019 and culture were unremarkable. Renal and bladder ultrasonography showed right renal agenesis (which was confirmed by renogram), normal bladder, and prostate with a seminal vesicle cyst on the right side $(61 \times 50$ $\mathrm{mm}$ ) which was confirmed by transrectal ultrasonography and CT Urogram . Semen analysis showed asthenozoospermia and he was HBsAg positive.

Cystoscopy showed bulging of the bladder base and normal ureteric orifice on the left side. The patient was successfully treated using transurethral endoscopic deroofing with cautery for hemostasis. The resectoscope was inserted through the urethra, into the bladder. The bladder was examined and then the bladder neck, prostatic urethra, and verumontanum area were evaluated. No hyperemia, bleeding, vascular malformations, varices, or neoplasms were observed. The bladder neck and prostatic urethra area were deviated to one side with loss of normal symmetry. The resectoscope was used to resect a 1cmlong and 1-cm-wide segment of tissue from the bladder neck to the verumontanum. The depth of resection was not more than $1 \mathrm{~cm}$. The unroofed seminal vesicle cyst contained a large amount of gelatinous milky fluid. The seminal vesicle cyst was irrigated with saline until it became clear. A smooth, reddish internal mucosa was visualized. The patient did not contain a mass in the cyst. The cyst wall was then cauterized using a loop electrode. A 22-French catheter was placed without irrigation, and the procedure ended. A Foley catheter was left for 7 days after surgery. Patientis advised for follow up after 3 months. The preoperative symptoms resolved afterderoofing.Post op USG scan was found satisfactory with almost complete resolution of the cyst. 

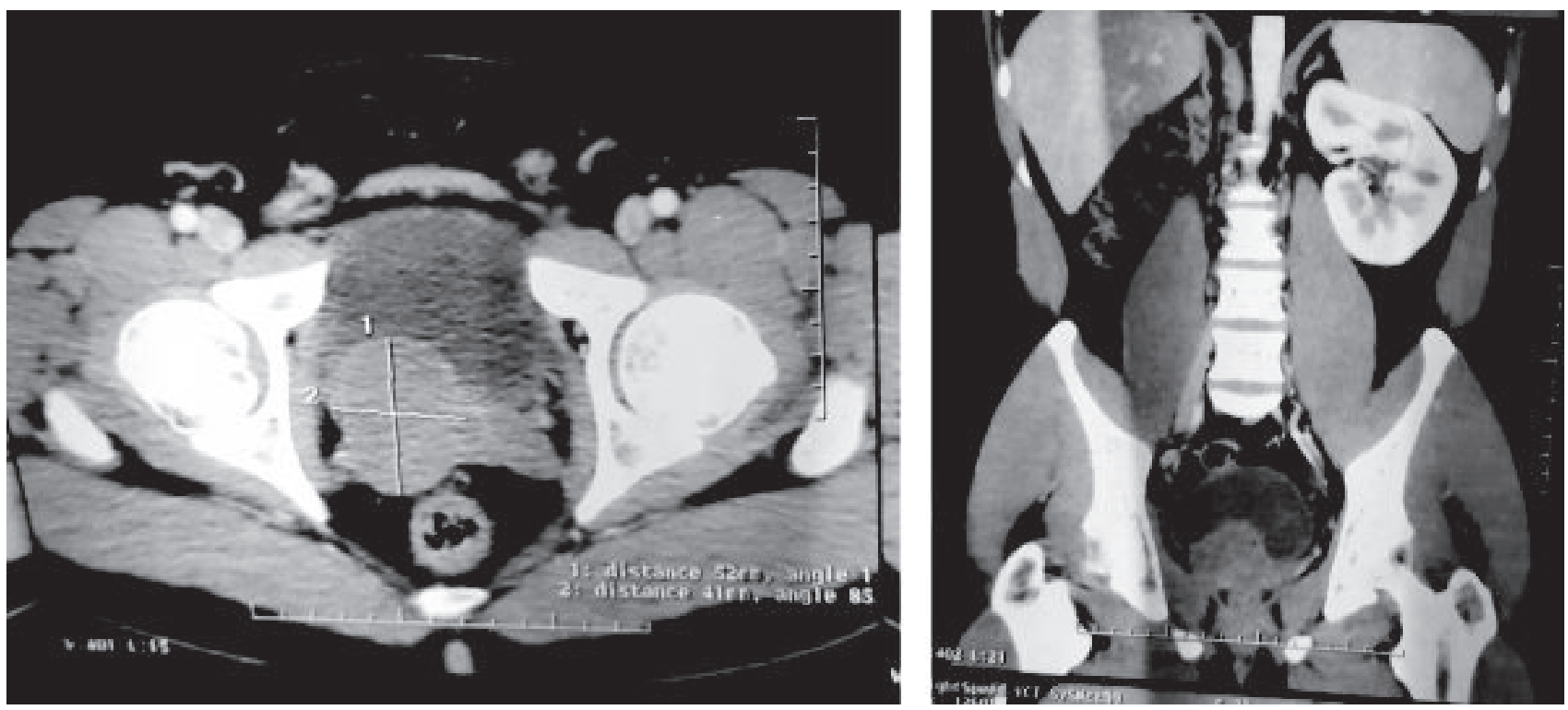

Fig.1: CT Scan showing large seminal vesicle cyst and Rt renal agenesis.

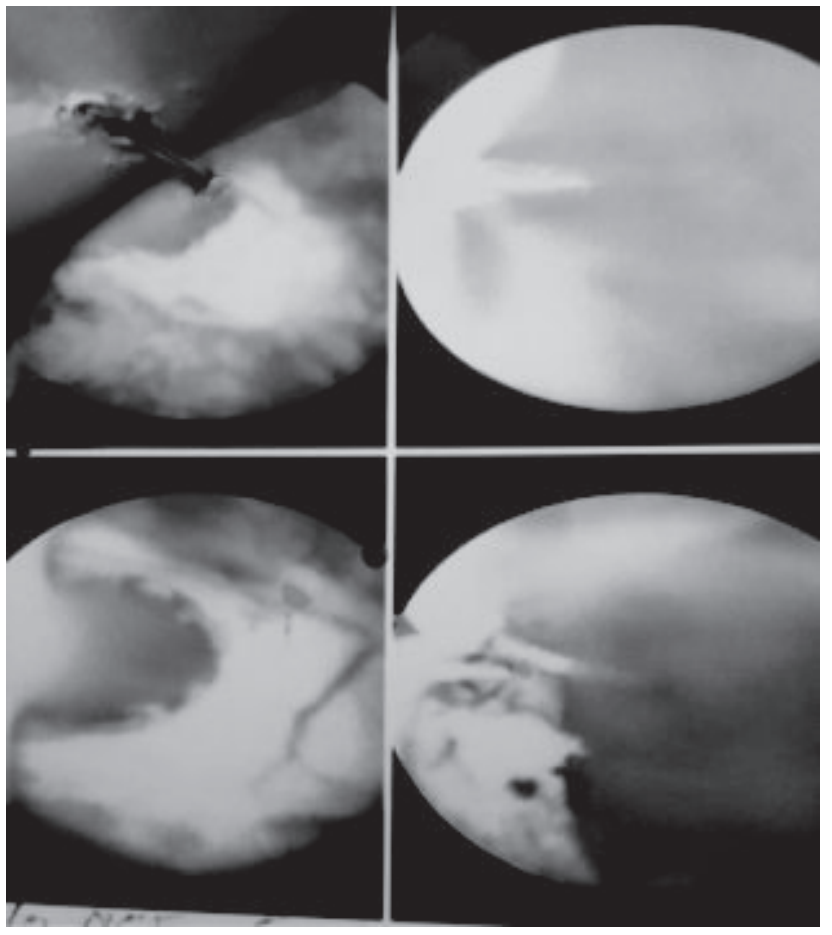

Fig.-2:Cystoscopy showing large cyst.

\section{Discussion}

Congenital or acquired seminal vesicle cysts involve less than $0.005 \%$ of the population. ${ }^{1}$ Congenital cysts, associated with ipsilateral malformation of the upper urinary tract, were described by Zinner in 1914[3,4]. Seminal vesicle cysts are characteristically unilateral with no side predilection and only two cases of bilateral seminal vesicle cysts have been reported in the literature[3]. They contain pale white fluid with spermatozoa and white blood cells, and are lined with cuboidal or flattened epithelium with a fibrous wall. ${ }^{2}$ Congenital cysts are associated with ipsilateral renal agenesis in two-thirds of the cases[2]. Inferior vena cava duplication, undescended testis, ectopic ureter, and hemivertebra have been reported in association with seminal vesicle cysts[5].

The acquired cyst is usually associated with inflammation or obstruction of ejaculatory ducts due to prostatitis, seminal vesiculitis, or prostatic surgery. ${ }^{2}$ Most of the cases are asymptomatic. The majority of seminal vesicle cysts are small $(<5 \mathrm{~cm})$ and present either asymptomatically or with infective or irritative urinary symptoms. Large cysts $(>8-10 \mathrm{~cm})$ may present with symptomaticobstruction of the bladder and/or bowel, and occur less frequently[3]. The diagnosis of these malformations is established mostly at the time of the greatest sexual activity when seminal fluidaccumulates in the seminal vesicle as a result of incomplete drainage. Most of the patients havesigns of infection on the initial evaluation[3]. Patients with seminal vesicle cysts may presentwith symptoms of bladder irritation, chronic recurrent prostatitis and recurrent epididymitis, painful ejaculation, urethral discharge, urgency, hesitancy, hematuria[6]. Occassionally patient may present with acute urinary retention, painon defecation, tenesmus, constipation, pelvic discomfort, perineal pain, testicular pain, abdominal mass, pelvic mass, infertility, and 
hematospermia[7,8,9]. Imaging modalities for the diagnosis ofseminal vesicle cysts are. Vasovesiculography, Transrectal ultrasonography (TRUS) and computed tomography scan, Magnetic resonance imaging (MRI), Cystoscopy, IVU.

Vaso-vesiculography may be required to document the lesion. This can be done transrectally, transurethrally, or intraoperatively by injection through the vas. All of these procedures are invasive and the last one carries the risk of vasal obstruction[7]. This is indicated only to differentiate the entity from other cystic malformations in the pelvis. These procedures detect the characteristics of the cyst and its relationship with adjacent pelvicstructures[7]. Transrectal ultrasonography is a standard method for evaluation of patients withhematospermia, azoospermia[10] low ejaculate volume, and is a useful procedure for the diagnosisof seminal vesicle cysts[8].

MRI is the best noninvasive procedure for visualization of seminal vesicle cysts and surrounding organs. ${ }^{5}$ The resolution of prostatic and vesicular anatomy was improved when an endorectal surface-coil (a device for increasing the resolution of the image) was used. Close proximity of endorectal coil to retrovesical structures, the spatial resolution reduction of section thickness, mutliplanar capability, and high soft tissue contrast makes MRI an appropriate noninvasive imaging method for the seminal tract[11]. Endorectal MRI should be reserved for selected patients when theresult of ultrasonography is not conclusive[12].

Cystoscopy is a necessary procedure for documenting the hemitrigone, absence of the ureteral orifice on the involved side, and extrinsic mass effect on the bladder[13].

IVU is a usual procedure for detection of concomitant urinary system abnormalities. Treatment should be considered for symptomatic cases $[5,14]$ and ranges from conservative medical treatment to surgical excision. ${ }^{14}$ Aspiration and injection of sclerosing agents have been used for small cysts, but recurrence and infection are disadvantages of this procedure[3,5]. Transurethral resection with unroofing of thecyst is a simple procedure, but the created diverticulummay predispose the patient to recurrent urinary tract infections and epididymitis[3, 5, 13, 15]. Complete removal of the cyst through laparoscopy or an open procedure using transperitoneal, transvesical, or retroperitoneal approach is the best decision.
Transperineal resection of seminal vesicle cysts carries the high risk of impotence even if a nerve sparing approach is attemepted[7]. Transcoccygeal resection of cyst isaccompanied by patient discomfort, rectal injury,and impotence[7]. Retrovesical resection of seminalvesicle cysts is considered in the patients requiringbilateral excision of small seminal vesicle cysts orbenign masses. Complications of this procedureinclude rectal injury, bladder laceration, andhemorrhage[7].

Paravesical resection of seminal vesicle cysts isindicated when resection of a large unilateral cystthat resides lateral and superior to the bladder with nephroureterectomy is needed[7]. Transvesicalresection of seminal vesicle cysts has beendescribed by numerous workers, with excellentexposure to anatomy and less morbidity comparedwith other approaches. Transvesical approach andlaparoscopic excision of cysts seem to be the bestmethods for resection of seminal vesicle cysts.

\section{Conclusion}

Seminal vesicle cysts are very rare and benign condition. Most of the patients remain almost asymptomatic. The symptomatic patients, large cysts should be treated. Endoscopic resection \& laparoscopic excision with experienced hands shows excellent result.

\section{References}

1 Gonzalez CM, Dalton DP. Endosopic incision of a seminal vesicle cyst. Urology. 1998; 51: $831-2$.

2 Razi A, Imani B. Seminal vesicle cyst presenting with lower urinary tract symptoms and huge abdominal mass. J Urol. 2000, 164: 1309 - 10.

3 Selli C, Bartoletti R, Travaglini F, et al. Surgical treatment of bilateral large seminal vesicle cysts associated withunilateral renoureteral agenesis. Urol Int. 1997; 58: 66 - 8.

4 Adeyoju AB, Taylor P, Payne SR. Congenital seminal vesicle cyst: an unusual but treatable cause of lowerurinary tract/genital symptoms. BJU Int. 2001; 87: $901-2$.

5 Callewaert P, De Coster M, Vuylsteke P, et al. Anal tenesmus caused by seminal vesicle cyst. Urology. 1997;49: $139-41$. 
6 Kajita Y, Shimizu Y, Takao N, et al. Seminal vesicle cyst with ipsilateral renal agenesis: a case report [in Japanese].Hinyokika kiyo. 2001; 47: 203 - 6.

7 Surya BV, Washecka R, Glasser J, et al. Cysts of the seminal vesicles: diagnosis and management. Br J Urol.1988; 62: 491 - 3.

8 Livingston L, Larsen CR. Seminal vesicle cyst with ipsilateral renal agenesis. AJR Am J Roentgenol. 2000;175: $177-80$.

9 Dominguez Dominguez M, Amaya Gutierrez J, Salazar Murillo R, et al. Cystic dysplasia in the seminal vesicle.Case report and literature review [in Espanish]. Actas Urol Esp. 1999; 23: 532 - 5.

10 Yassa NA, Keesara S. Role of transrectal ultrasonography in evaluating the cause of azoospermia. Can Assoc RadiolJ. 2001; 52: 266 -8 .

11 Gruber H, Rauchenwald M, Breini E, et al. The role of endorectal surface-coil MRI in the diagnosis of ectopicinsertion of the ureter into a seminal vesicle cyst. $\mathrm{Br} J$ Urol. 1996; 78: 306 - 8.

12 Engin G, Kadioglu A, Orhan I, et al. Transrectal US and endorectal MR imaging in partial and completeobstruction of the seminal duct system. A comparative study. Acta Radiol. 2000; 41: 288 $-95$.

13 Zaontz MR, Kass EJ. Ectopic ureter opening into seminal vesicle cyst associated with ipsilateral renal agenesis.Urology. 1987; 29: 523 - 5.

14 Gallmetzer J, Gozzi C, Dolif R, et al. Seminal vesicle cysts (and ejaculatory duct cysts) with ipsilateral renalagenesis. Report of five cases and review of literature. Minerva Urol Nefrol. 1999; 51: $27-31$.

15 van den Ouden D, Blom JH, Bangma $\mathrm{C}$, et al. Diagnosis and management of seminal vesicle cysts associated withipsilateral renal agenesis: a pooled analysis of 52 cases Eur Urol. 1998; 33: $433-40$. 